\title{
Comunicação
}

[Communication]

\section{Deteç̧ão e avaliação do perfil de sensibilidade antimicrobiana de enterobactérias isoladas de periquitos cara-suja (Pyrrhura griseipectus) em cativeiro}

\author{
[Detection and evaluation of the antimicrobial sensibility profile of enterobacteria \\ isolated from captive Grey-breasted parakeet (Pyrrhura griseipectus)] \\ D.N. Machado, E.S. Lopes, Á.H. Albuquerque, W.G.A. Bezerra, R.V. Horn, S.V.G. Lima, \\ R.A.S. Siqueira, A.J.F. Beleza, F.R. Oliveira, W.M. Cardoso, R.S.C. Teixeira
}

Universidade Estadual do Ceará - UECE - Fortaleza, CE

Os periquitos cara-suja pertencem à ordem Psittaciformes, no qual é inclusa a família Psittacidae, constituída por papagaios, araras e periquitos. Endêmicas do Nordeste brasileiro, essas aves somente são encontradas em três regiões do estado do Ceará, mais especificamente na Serra de Baturité e nos municípios de Quixadá e Ibaretama (Girão et al., 2010). Neste exposto, por apresentarem isolacionismo territorial, juntamente com a reduzida existência de exemplares em vida livre, são classificadas como aves em perigo de extinção pela lista oficial de espécies da fauna brasileira ameaçada de extinção (Brasil, 2014).

Mediante poucos estudos serem realizados para determinação da composição da microbiota entérica das diversas espécies de psitacídeos, inclusive com o periquito cara-suja, lacunas científicas acerca dessa temática ainda existem, sendo uma das hipóteses defendidas a de que seu arranjo microbiano é constituído essencialmente por bactérias Gram-positivas (Flammer e Drewes, 1988). Desse modo, a presença de bactérias Gram-negativas, com destaque para as pertencentes à família Enterobacteriaceae, seria um potencial indicativo de enfermidade ou desequilíbrio fisiológico (Mattes et al., 2005).

Outra problemática, além do albergue de bactérias com potencial zoonótico, refere-se ao fenômeno da resistência microbiana, no qual progressivamente se tem evidenciado o papel dos psitacídeos como hospedeiros de bactérias resistentes a antibióticos de importância médica, relevantes tanto para a terapêutica humana

Recebido em 16 de outubro de 2015

Aceito em 9 de agosto de 2016

E-mail: deboranishi@gmail.com quanto para a animal (Hidasi et al., 2013). Por conseguinte, é preocupante a capacidade de que aves de cativeiro possam abrigar enterobactérias resistentes, em especial cepas multirresistentes, pois são passíveis de as disseminarem no ambiente, bem como de transmiti-las diretamente para outros animais, inclusive para o homem. Desse modo, esta pesquisa teve por objetivo detectar a presença de enterobactérias em periquitos cara-suja de cativeiro, avaliando o perfil de sensibilidade aos antimicrobianos apresentado pelas cepas isoladas.

Para tanto, foram coletados 25 suabes clocais individuais provenientes de periquitos cara-suja de diferentes estágios de idade, alocados em um criadouro comercial e conservacionista no estado do Ceará, Brasil. Todas as aves encontravam-se aparentemente saudáveis, sendo alojadas em recintos de criação telados, com piso de cimento, e separadas das demais espécies de animais criados nesse centro. No tocante aos aspectos sanitário-ambientais, diariamente, era realizado higienização desse ambiente, juntamente com a troca do conteúdo dos comedouros e bebedouros duas vezes por dia.

As amostras obtidas foram dispostas em tubos comportando água peptonada tamponada (Himedia, Mumbai, Índia), sendo conservadas em isopor contendo gelo reciclável, com o intuito de preservação de suas propriedades intrínsecas. O material coletado foi transportado para o Laboratório de Estudos Ornitológicos (Labeo) da Faculdade de Veterinária, pertencente à Universidade Estadual do Ceará (UECE), para imediato processamento microbiológico. Após 
incubação prévia em estufa bacteriológica por $24 \mathrm{~h}$ a $37^{\circ} \mathrm{C}$, tempo e temperatura padronizados para todas as etapas posteriores, alíquotas de $1 \mathrm{~mL}$ do material primário foram transferidas para tubos com caldo brain heart infusion (Himedia, Mumbai, Índia) e tubos com caldo selenito cistina (Himedia, Mumbai, Índia), sendo estes dispostos na estufa.

Sequencialmente, frações dos caldos foram semeadas em placas com ágar MacConkey (Himedia, Mumbai, Índia) e em ágar Hektoen (Himedia, Mumbai, Índia), destinadas à estufa bacteriológica. Colônias com características morfológicas de enterobactérias foram selecionadas nesses meios e identificadas por meio da seguinte bateria de provas bioquímicas: averiguação das características fermentativas clássicas no ágar TSI (tríplice, açúcar, ferro), reações oxidativas no ágar LIA, produção de sulfeto, indol e motilidade no ágar SIM, bem como atividades químicas na reação de vermelho de metila, reação de VogesProskauer, ornitina descarboxilase, manitol, arabinose, rafinose, dulcitol, adonitol, inositol, urease, ramnose, citrato, malonato, glicose e lactose (Acumedia, lansing, Michigan, EUA; Difco, Le pont de craix, França; Himedia, Mumbai, Índia).

Para averiguação do perfil de resistência das enterobactérias, previamente identificadas, foi empregado o método de disco-difusão com o ágar Mueller-Hinton, com a metodologia de acordo com os parâmetros do Clinical and Laboratory Standards Institute - CLSI (2012). Os discos de antibióticos foram selecionados mediante $\quad 0$ protocolo padrão do laboratório, sendo empregados: azitromicina $(15 \mu \mathrm{g}), \quad$ ceftiofur $(30 \mu \mathrm{g})$, tetraciclina $(30 \mu \mathrm{g})$, sulfametoxazol-trimetoprim $(25 \mu \mathrm{g})$, cloranfenicol $(30 \mu \mathrm{g})$, estreptomicina $(10 \mu \mathrm{g})$, ciprofloxacino $(5 \mu \mathrm{g}), \quad$ gentamicina $(10 \mu \mathrm{g})$ e polimixina B $(300 \mu \mathrm{g})$ (Laborclin, Pinhais, PR, Brasil).

Os discos de antimicrobianos foram ordenados em placa contendo o ágar Mueller-Hinton, previamente semeada com a amostra bacteriana a ser analisada. Após a incubação em estufa bacteriológica por $24 \mathrm{~h}$ a $37^{\circ} \mathrm{C}$, os resultados foram interpretados de acordo com medição manual das zonas de inibição circundantes aos discos, seguindo a orientação de mensuração estabelecida pelo CLSI (2012). Desse modo, os isolados foram classificados em sensíveis, intermediários e resistentes, sendo empregada a cepa de Escherichia coli ATCC 25922 como controle. Este estudo foi executado sob aprovação do Comitê de Ética para o Uso de Animais (Ceua-UECE), com numeração 4832011/14.

Do total de amostras avaliadas, 10 apresentaram crescimento bacteriano, correspondendo a um porcentual de 40\% (10/25). Percentual inferior foi detectado por Bangert et al. (1988), que evidenciaram o isolamento de somente seis cepas de bacilos Gram-negativos de 61 psitacídeos de cativeiro, em contraste ao estudo de Lopes et al. (2015), que averiguaram a presença de enterobactérias em cerca de $71 \%$ dos 167 psitacídeos investigados.

Por consequência, embora na literatura existam resultados variáveis, no presente estudo esse número reduzido de isolamento pode estar relacionado às boas condições sanitárias encontradas na ambiência nas quais esses periquitos se encontravam, sendo obedecidas as práticas de biossegurança exigidas para uma criação adequada de aves em cativeiro (Evans et al., 2014). Nesse aspecto, verifica-se que, entre as práticas de manejo que possam afetar a composição de microbiota entérica, uma delas estaria associada a uma antibioticoterapia prévia, responsável por acarretar a eliminação parcial de bactérias- alvo.

Foi possível obter a detecção de 14 enterobactérias pertencentes aos gêneros Escherichia, Hafnia, Pantoea, Klebsiella, Enterobacter e Serratia. Nesse âmbito, as três bactérias de maior isolamento corresponderam à Escherichia coli, com quatro cepas $(28,6 \%)$, Pantoea agglomerans e as do gênero Klebsiella, ambas com três cepas $(21,4 \%)$. Quanto ao gênero Enterobacter, foram quantificadas duas cepas $(14,3 \%)$ e um único isolamento de Serratia spp. $(7,2 \%)$ e Hafnia alvei (7,2\%). Adicionalmente, neste estudo foi possível averiguar a presença bacteriana tanto em periquitos filhotes como em adultos de todas as gerações familiares dessa ave nesse ambiente de criação (Tab. 1).

Escherichia coli como a enterobactéria de maior teor de isolamento em psitacídeos já foi determinada em estudos posteriores (Bangert, 
1988), sendo este considerado um resultado frequente em estudos de avaliação de microbiota intestinal de psitacídeos clinicamente saudáveis (Evans et al., 2014). Apesar de ser um achado condizente com a literatura de aves silvestres criadas em cativeiro, essa bactéria tem sido associada à origem de afecções primárias ou secundárias em psitacídeos, sendo passível de acarretar sinais gastrintestinais, nervosos e a morte súbita da ave (Godoy, 2007).

As demais enterobactérias isoladas são consideradas como agentes microbianos oportunistas, proporcionando o desenvolvimento de uma enfermidade, principalmente, em aves imunodeprimidas (Godoy, 2007). Desse modo, a problemática do albergue dessas enterobactérias pelos periquitos neste estudo reside na possibilidade da geração de alguma enfermidade em decorrência de alterações ambientais que a criação em cativeiro possa trazer, tais como manejo humano, estresse ou alterações na dieta, desencadeando na suscetibilidade da ave a bactérias, que, em condições normais, apresentariam papel inócuo.

Tabela 1. Identificação da ave, sexo, idade, geração familiar e isolado bacteriano provenientes de periquitos cara-suja de cativeiro, alocados no Ceará, Brasil

\begin{tabular}{|c|c|c|c|c|}
\hline Identificação da ave & Sexo & Idade & Geração & Isolado bacteriano \\
\hline 1658 & Macho & Filhote & $\mathrm{F} 2$ & Pantoea agglomerans, Enterobacter spp., Serratia spp. \\
\hline 1666 & Fêmea & Filhote & $\mathrm{F} 2$ & Pantoea agglomerans, Enterobacter spp., Klebsiella spp. \\
\hline 1657 & Fêmea & Filhote & F2 & Escherichia coli \\
\hline 1660 & Macho & Filhote & F2 & Ausente \\
\hline 1554 & Fêmea & Adulto & $\mathrm{F} 2$ & Ausente \\
\hline 1333 & Macho & Adulto & $\mathrm{F} 2$ & Ausente \\
\hline 1147 & Fêmea & Adulto & $\mathrm{F} 1$ & Ausente \\
\hline 1146 & Fêmea & Adulto & $\mathrm{F} 1$ & Ausente \\
\hline 109 & Macho & Adulto & $\mathrm{P}$ & Klebsiella spp., Escherichia coli \\
\hline 906 & Macho & Adulto & $\mathrm{F} 1$ & Pantoea agglomerans \\
\hline 907 & Macho & Adulto & $\mathrm{F} 1$ & Ausente \\
\hline 895 & Fêmea & Adulto & F1 & Ausente \\
\hline 893 & Macho & Adulto & $\mathrm{F} 1$ & Ausente \\
\hline 615 & Macho & Adulto & F1 & Klebsiella spp. \\
\hline 1136 & Fêmea & Adulto & $\mathrm{F} 1$ & Ausente \\
\hline 1128 & Macho & Adulto & $\mathrm{F} 1$ & Ausente \\
\hline 899 & Fêmea & Adulto & $\mathrm{F} 1$ & Ausente \\
\hline 910 & Fêmea & Adulto & $\mathrm{F} 1$ & Escherichia coli \\
\hline 898 & Fêmea & Adulto & F1 & Ausente \\
\hline 1138 & Macho & Adulto & $\mathrm{F} 1$ & Hafnia alvei \\
\hline 618 & Macho & Adulto & $\mathrm{F} 1$ & Ausente \\
\hline 1408 & Fêmea & Adulto & $\mathrm{F} 1$ & Ausente \\
\hline 1142 & Fêmea & Adulto & $\mathrm{F} 1$ & Escherichia coli \\
\hline 1444 & Macho & Adulto & $\mathrm{F} 1$ & Ausente \\
\hline 607 & Fêmea & Adulto & $\mathrm{F} 1$ & Ausente \\
\hline
\end{tabular}

P: parenteral, F1: primeira geração de filhotes, F2: segunda geração de filhos.

As bactérias isoladas apresentaram grau variável de resistência aos antibióticos testados, indicando sensibilidade total às substâncias ceftiofur, cloranfenicol, ciprofloxacina e polimixina B. Os antibióticos aos quais as bactérias apresentaram maior resistência foram, em ordem crescente, tetraciclina, azitromicina e sulfametoxazoltrimetoprim, com valores percentuais correspondentes a $21 \%(3 / 14), 43 \%(6 / 14)$ e $57 \%$ (8/14) (Tab. 2).

Os antibióticos selecionados apresentam como alvo bactérias Gram-negativas, sendo incluídas enterobactérias; assim, tanto neste estudo como em outros realizados com aves silvestres (Santos et al., 2010; Hidasi et al., 2013), tem se evidenciado cada vez mais o surgimento de bactérias resistentes aos antimicrobianos de escolha para o tratamento de inúmeras infecções.

Dessa forma, apesar da probabilidade da manifestação natural da resistência microbiana às substâncias antibióticas (Nascimento et al., 2003), as fontes mais prováveis da origem desse fenômeno relacionam-se tanto ao contato direto com os tratadores, responsáveis pelo manejo dos animais do criadouro, o qual possibilitaria uma troca de microrganismos com genes de resistência (Santos et al., 2010), quanto a uma possível exposição prévia a um antimicrobiano em um tratamento profilático. 
Deteç̧ão e avaliação...

Tabela 2. Frequência absoluta do perfil de sensibilidade aos antimicrobianos apresentados pelas cepas isoladas

\begin{tabular}{|c|c|c|c|c|c|c|c|c|c|c|c|c|c|c|c|c|c|c|c|c|c|}
\hline \multirow[b]{3}{*}{ Antibióticos } & \multicolumn{18}{|c|}{ Enterobactérias isoladas (n amostral) } & & & \\
\hline & \multicolumn{3}{|c|}{$\begin{array}{c}\text { Escherichia } \\
\text { coli }\end{array}$} & \multicolumn{3}{|c|}{$\begin{array}{c}\text { Pantoea } \\
\text { agglomerans }\end{array}$} & \multicolumn{3}{|c|}{$\begin{array}{l}\text { Enterobacter } \\
\text { spp. }\end{array}$} & \multicolumn{3}{|c|}{$\begin{array}{c}\text { Hafnia } \\
\text { alvei }\end{array}$} & \multicolumn{3}{|c|}{$\begin{array}{l}\text { Klebsiella } \\
\text { spp. }\end{array}$} & \multicolumn{3}{|c|}{$\begin{array}{l}\text { Serratia } \\
\text { spp }\end{array}$} & \multicolumn{3}{|c|}{ Total } \\
\hline & $\mathrm{S}$ & $\mathrm{I}$ & $\mathrm{R}$ & $\mathrm{S}$ & $\mathrm{I}$ & $\mathrm{R}$ & $\mathrm{S}$ & $\mathrm{I}$ & $\mathrm{R}$ & $\mathrm{S}$ & $\mathrm{I}$ & $\mathrm{R}$ & $\mathrm{S}$ & $\mathrm{I}$ & $\mathrm{R}$ & $\mathrm{S}$ & $\mathrm{I}$ & $\mathrm{R}$ & $\mathrm{S}$ & $\mathrm{I}$ & $\mathrm{R}$ \\
\hline AZI & 0 & 2 & 2 & 0 & 2 & 1 & 0 & 1 & 1 & 0 & 1 & 0 & 0 & 2 & 1 & 0 & 0 & 1 & 0 & 8 & 6 \\
\hline $\mathrm{CTF}$ & 4 & 0 & 0 & 3 & 0 & 0 & 2 & 0 & 0 & 1 & 0 & 0 & 3 & 0 & 0 & 1 & 0 & 0 & 14 & 0 & 0 \\
\hline TET & 3 & 0 & 1 & 2 & 0 & 1 & 2 & 0 & 0 & 1 & 0 & 0 & 2 & 0 & 1 & 1 & 0 & 0 & 11 & 0 & 3 \\
\hline SUT & 2 & 0 & 2 & 0 & 0 & 3 & 2 & 0 & 0 & 0 & 0 & 1 & 1 & 0 & 2 & 1 & 0 & 0 & 6 & 0 & 8 \\
\hline CLO & 4 & 0 & 0 & 3 & 0 & 0 & 2 & 0 & 0 & 1 & 0 & 0 & 3 & 0 & 0 & 1 & 0 & 0 & 14 & 0 & 0 \\
\hline EST & 2 & 1 & 1 & 2 & 1 & 0 & 2 & 0 & 0 & 1 & 0 & 0 & 3 & 0 & 0 & 1 & 0 & 0 & 11 & 2 & 1 \\
\hline CIP & 4 & 0 & 0 & 3 & 0 & 0 & 2 & 0 & 0 & 1 & 0 & 0 & 3 & 0 & 0 & 1 & 0 & 0 & 14 & 0 & 0 \\
\hline GEN & 4 & 0 & 0 & 3 & 0 & 0 & 1 & 0 & 1 & 1 & 0 & 0 & 3 & 0 & 0 & 1 & 0 & 0 & 13 & 0 & 1 \\
\hline POL & 4 & 0 & 0 & 3 & 0 & 0 & 2 & 0 & 0 & 1 & 0 & 0 & 3 & 0 & 0 & 1 & 0 & 0 & 14 & 0 & 0 \\
\hline
\end{tabular}

P: Pantoea. AZI: azitromicina, CTF: ceftiofur, TET: tetraciclina, SUT: sulfametoxazol-trimetoprim, CLO: cloranfenicol, EST: estreptomicina, CIP: ciprofloxacina, GEN: gentamicina, POL: polimixina B, S: sensibilidade, I: intermediário, $\mathrm{R}$ : resistente

Por conseguinte, embora não se tenham evidenciado enterobactérias com elevado teor de resistência antimicrobiana, a presença de cepas resistentes, inclusive a mais de um antibiótico, torna-se um problema, pois existe a possíbilidade do desenvolvimento de cepas multirresistentes, como a transferência de genes de resistência para outras espécies bacterianas, passíveis de desencadearem um quadro epidemiológico de disseminação para os tratadores e para outros animais provenientes do mesmo criadouro.

Por meio deste estudo, portanto, foi possível evidenciar o carreio moderado de enterobactérias em periquitos cara-suja, tanto de filhotes quanto de adultos, apresentando caracteres de resistência a antimicrobianos. Faz-se necessário, então, acompanhamento microbiológico e clínico das aves para averiguação de futuras enfermidades que possam ser originárias dessas bactérias, bem como a realização prévia de testes de sensibilidade microbiana para a efetuação da escolha do antibiótico a ser utilizado, possibilitando uma terapia adequada e evitando o surgimento de cepas resistentes com potencial risco sanitário.

Palavras-chave: isolamento, Enterobacteriaceae, psitacídeos, resistência

\begin{abstract}
This study was conducted to detect enterobacteria in captive Grey-breasted parakeet from a commercial breeding located in the state of Ceara. 25 individual cloacal swabs were collected and this material was subjected to microbiological processing to obtain the bacterial isolation, identification, and evaluation of the sensitivity profile to antimicrobials. The bacterial isolation in ten samples was determined, belonging to the genera Enterobacter, Hafnia, Serratia, Escherichia, Pantoea and Klebsiella, in which these last three corresponded to the bacteria most isolated, with respective percentages of $28.6 \%, 21.4 \%$, and 21.4\%. As for the sensitivity profile, antibiotics to which the bacteria showed more resistance were trimethoprim-sulfamethoxazole (57\%), tetracycline (21\%), and azithromycin (43\%). Thus, it was shown that the parakeets were carriers of Enterobacteriaceae with resistance characteristics.
\end{abstract}

Keywords: isolation, Enterobacteriaceae, psittacine, resistance

\section{REFERÊNCIAS}

BANGERT, R.L.; CHO, A.B.R.; WIDDERS, A.P.R. et al. Survey of aerobic bacteria and fungi in the feces of healthy psittacine birds. Avian Dis., v.32, p.46-52, 1988 .
BRASIL. Ministério do Meio Ambiente. Portaria do MMA n.444/2014. Reconhecer como espécies da fauna brasileira ameaçadas de extinção aquelas constantes da "Lista Nacional Oficial de Espécies da Fauna Ameaçadas de Extinção" Diário Oficial da União, Brasília, 17 dez. 2014. p.121-126. 
EVANS, E.E.; MITCHELL, M.A.; WHITTINGTON, J.K. et al. Measuring the level of agreement between cloacal gram's stains and bacterial cultures in Hispaniolan Amazon parrots (Amazona ventralis). J. Avian Med. Surg., v.28, p.290-296, 2014.

FLAMMER, K.; DREWES, L.A. Species-related differences in the incidence of gram-negative bacteria isolated from the cloaca of clinically normal psittacine birds. Avian Dis., v.32, p.79-83, 1988.

GIRÃO, W.; ALBANO, C.; CAMPOS, A.A. Inselbergs as habitat to the critically endangered greybreasted parakeet (Pyrruhura griseipectus), an endemic species from northeastern Brazil. Rev. Bras. Ornitol., v.18, p.130-132, 2010.

GODOY, S.N. Psittaciformes (arara, papagaio, periquito). In: CUBAS, Z.S.; SILVA, J.C.R.; CATÃO-DIAS, J.L. Tratado de animais selvagens. São Paulo: ROCA, 2007. p.222-251.

HIDASI, H.W.; HIDASI NETO, J.; MORAES, D.M.C. et al. Enterobacterial detection and Escherichia coli antimicrobial resistance in parrots seized from the illegal wildlife trade. J. Zoo Wildl. Med., v.44, p.1-7, 2013.
LOPES, E.S.; MACIEL, W.C.; ALBUQUERQUE, A.H. et al. Prevalence and antimicrobial resistance profile of enterobacteria isolated from psittaciformes of illegal wildlife trade. Acta Sci. Vet., v.43, p.1-9, 2015.

MATTES, B.R.; CONSIGLIO, A.S.; ALMDEIDA, B.Z. et al. Influência da biossegurança na colonização intestinal por Escherichia coli em psitacídeos. Arq. Inst. Biol., v.72, p.13-16, 2005.

NASCIMENTO, A.M.A.; CURSINO, L.; GONÇALVES-DORNELAS, H. et al. Antibioticresistant gram-negative bacteria in birds from the Brazilian Atlantic Forest. Condor, v.105, p.358-361, 2003.

PERFORMANCE standards for antimicrobial susceptibility testing; twenty-second informational supplement. Wayne: CLSI, 2012. [231p.]. Disponível em: $<$ http://mazums.ac.ir/dorsapax/userfiles/file/moave nat\%20darman/M100-S22.pdf >. Accessado em: 4 Out. 2015.

SANTOS, H.F.; FLÔRES, M.L.; LARA, V.M. et al. Microbiota cloacal aeróbia de cracídeos cativos no Rio Grande do Sul e sua susceptibilidade a antimicrobianos. Pesqui. Vet. Bras., v.30, p.1077$1082,2010$. 